\title{
The epidemiological, clinical and evolutive aspects of the SARS-CoV-2 infection - an intermediary analysis of the cases from "Victor Babes" Clinical Hospital in Craiova, Romania
}

\author{
Florentina Dumitrescu ${ }^{1,2}$, Adina Andreea Turcu ${ }^{1,2}$, Livia Dragonu ${ }^{1,2}$, \\ Andreea-Cristina Stoian ${ }^{1}$, Iulian Diaconescu ${ }^{1,2}$, Radu Diaconu ${ }^{1,3}$, Lucian Giubelan ${ }^{1,2}$ \\ ${ }^{1}$ University of Medicine and Pharmacy, Craiova, Romania \\ 2"Victor Babes" Hospital of Infectious Diseases an Pneumology, Craiova, Romania \\ ${ }^{3}$ Filantropia Clinical Hospital, Craiova, Romania
}

\begin{abstract}
Objective. To report the experience of „Victor Babes” Hospital from Craiova, Romania, regarding epidemiological and clinical features of SARS-CoV-2 infection.

Material and methods. Retrospective study, from the 1st of March to the 31st of May, with the analysis of clinical and paraclinical data of the COVID-19 diagnosed patients.

Results. 245 COVID-19 hospitalized patients, age median, 39 years $(0,81), 128(52.2 \%)$ were men, 133 $(54.3 \%)$ with close contact with a previously confirmed case, $71(28.9 \%)$ imported cases. Three important familial outbreaks $(20,13$, and 9 cases respectively) and one work outbreak (28 gendarmes) were identified; 29 medical workers were hospitalized. The most frequent clinical presentation were cough $-110(57.9 \%)$ and fever - $86(45.3 \%)$. There were $10(4.1 \%)$ deaths, $192(78.4 \%)$ recovered and 43 still hospitalized patients at the end of the study. The median duration of hospitalization in recovered patients was 13.5 days $(8,35)$. Death associated with older age and comorbidities.

Conclusions. Among patients hospitalized with SARS-CoV-2 infection in Craiova, were identified several important outbreaks; clinical symptoms were frequently like a mild respiratory tract infection; death associated with older age and comorbidities.
\end{abstract}

Keywords: SARS-CoV-2, COVID-19, epidemiology

\section{BACKGROUND}

COVID-19 (acronym derived from coronavirus disease 2019) is the name of the disease determined by a new strain of coronavirus (SARS-CoV-2), with an evolutive potential towards acute respiratory distress syndrome [1].

Coronaviruses are found in natural hosts such as bats but have also been detected in various animal species (MERS-CoV in camels, SARS-CoV-1 in civet cats) [2-4].

SARS-CoV-2, an ARN virus with a zoonotic origin, had probably had an adaptive evolution in intermediary hosts, the transfer to humans being facilitated by the receptors' resemblance (the angiotensin 2 converting enzyme - ACE2), which allowed a lower species barrier for the animal-human viral transmission [5]. 
The recent COVID-19 outburst in Wuhan [6] became a public health and international worry emergency due to the new aspects related to the therapeutic challenges, the specific prophylaxis and the high contagiousness. Being a new virus and not having a previous post exposure immunization, make the entire human population susceptible to the SARS-CoV-2 infection.

COVID-19 has displayed an exponential increase of cases' number starting with the end of February 2020 , changing into an intensive community transmission, which affected over 180 countries worldwide [7]. In Europe, the fast rise in the number of cases in countries such as Italy and Spain represented a major challenge which has put an enormous pressure on the medical care system [8].

Preliminary data from the UE/SEE countries show an approximate $30 \%$ of the diagnosed COVID-19 cases have required hospitalization, with a $12 \%$ mortality [8]. The performed estimations showed that the risk of catching the disease, the severe disease forms and mortality are for people over 60 years old and for those with other comorbidities (e.g. high blood pressure, diabetes, cardiovascular diseases, chronic respiratory diseases, cancers) [9]. It has also been pointed out that the percentage of affected men was higher than women and that children have a lower risk in developing severe symptoms or forms than adults, forming a small part (under 5\%) of the whole COVID-19 reported cases [8].

The testing approaches through RT-PCR (reverse transcription polymerase chain reaction) are adapted to the national and local situation, with preestablished high priority patient categories.

COVID-19 symptoms have varying severity, $\mathrm{Wu}$ and McGoogan reported on their studied cases, a percentage of 81 asymptomatic or easy forms, $14 \%$ severe ones (hypoxia, dyspnea, spread of the pulmonary injury $>50 \%$ in $24-48$ hours), $5 \%$ critical (shock, respiratory failure, multiorgan disfunction) and $2.3 \%$ fatal [10]. Reports show that the clinical deterioration can happen fast, most frequently in the second week of illness [8].

In Romania, according to the data from the National Public Health Institute, until $31^{\text {st }}$ of May 2020, 19257 COVID-19 cases have been confirmed, with 1262 deaths ( $6.5 \%$ mortality). The deceased patients had at least one comorbidity (90.7\%), 76.4\% being over 60 years old, $58.7 \%$ men [11]. The Dolj county has 223 registered cases, with an incidence of under 10/100.000 inhabitants, lower than other Romanian regions [12].

\section{OBJECTIVES}

We aimed the evaluation of the epidemiological, clinical and evolutive aspects of the COVID-19 cases hospitalized in „Victor Babes“ Infectious Diseases and Pneumology Clinical Hospital in Craiova, Romania.

\section{MATERIALS AND METHOD}

We conducted a retrospective study, with the analysis of the data mentioned in the medical records for the COVID-19 hospitalized patients, between the $1^{\text {st }}$ of March 2020 and the $31^{\text {st }}$ of May 2020. We evaluated the demographic, epidemiological and clinical data, the biological parameters and also the results from the investigations and paraclinical data. The SARS-CoV-2 infection confirmation has been made through RT-PCR from the nasopharyngeal exudates, and the patients' discharge was made only after obtaining two consecutive negative RT-PCR SARS$\mathrm{CoV}-2$ results (harvested at minimum 24 hours interval). We used Fisher test to establish the correlation between different parameters, the value $p \leq 0.05$ being considered statistically significant.

\section{RESULTS}

The studied group consisted of 245 patients hospitalized with COVID-19, between the $1^{\text {st }}$ of March 2020 and the $31^{\text {st }}$ of May 2020 in the Victor Babeș Infectious Diseases and Pneumology Clinical Hospital in Craiova. Most cases have been admitted between the $24^{\text {th }}$ and the $30^{\text {th }}$ of April 2020 (figure 1).

The patients' characteristics have been summarized in Table 1. The age median was 39 years, men were most affected (men/women:1.09) with a predominance of cases from the urban area (urban/rural:2.6).

Children represented a $9.8 \%$ of cases ( 3 infants were hospitalized, aged 3, 4 and 8 months) and 39 patients $(15.9 \%)$ were over 60 years old (figure 2); there were 3 cases in pregnant women.

There were hospitalized 213 patients from the Dolj county and 23 from the nearby counties $(10-$ Olt, 6 - Gorj, 11 - Mehedinți, 5 - Vâlcea); the biggest num- 




FIGURE 1. The weekly numeric case repartition

TABLE 1. COVID-19 patients' characteristics

\begin{tabular}{|l|c|c|}
\hline & Number & Percentage \\
\hline Age, median (IQR), years & $39(0,81)$ & \\
\hline Sex, masculine & 128 & 52.2 \\
\hline Area of provenience, urban & 177 & 72.2 \\
\hline Imported cases & 71 & 28.9 \\
\hline Contacts of previously con ases & 133 & 54.3 \\
\hline Healthcare workers & 29 & 11.8 \\
\hline $\begin{array}{l}\text { P om the debut to the } \\
\text { hospital admission, median (IQR), days }\end{array}$ & $4(0,12)$ & \\
\hline Severe form & 28 & 11.4 \\
\hline
\end{tabular}

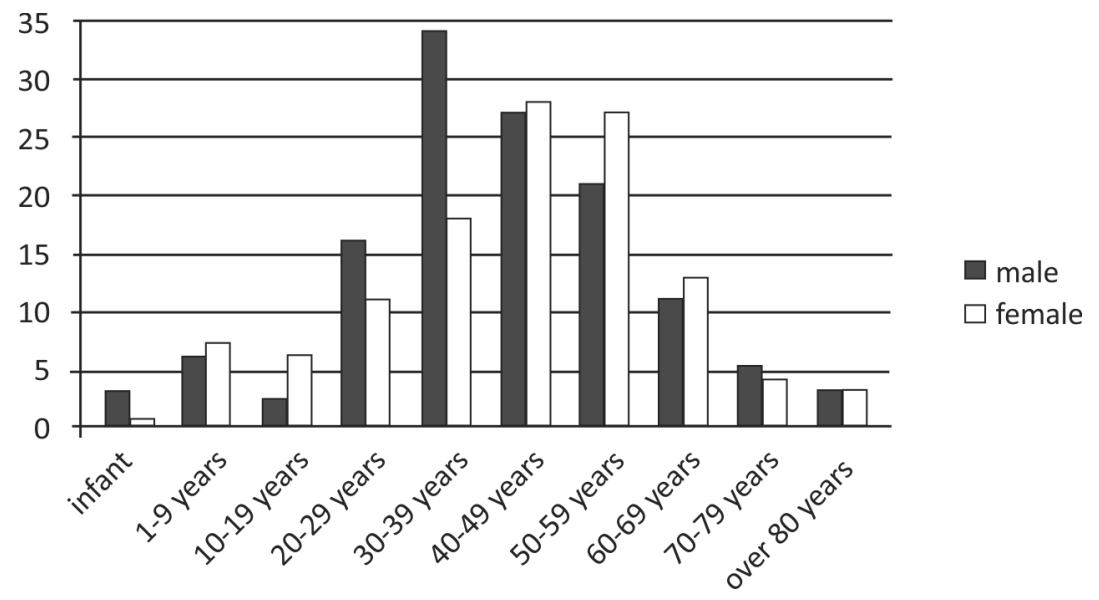

FIGURE 2. The numeric repartition of cases on age groups and sex

ber of patients from the Dolj county came from the urban area 137 cases (figure 3 ).

The epidemiological link has been an orientation factor in diagnosing the cases, 133 patients (54.3\%) had had contact with a previously positive confirmed person. Imported cases represented $28.9 \%$ from the studied group, most of them being associated with history of recent travelling in Italy (28), United King- dom (22) and Spain (5). We identified 3 family outbreaks with a large number of cases - 20,13 and 9 and a work outbreak 28 gendarmes; there were 29 cases (11.8\%) of healthcare workers ( 2 doctors, 19 nurses, 8 nursemaids), none of them were working in our hospital.

Among comorbidities, most frequent were the cardiovascular ones: 81 patients (33.1\%) with high blood 


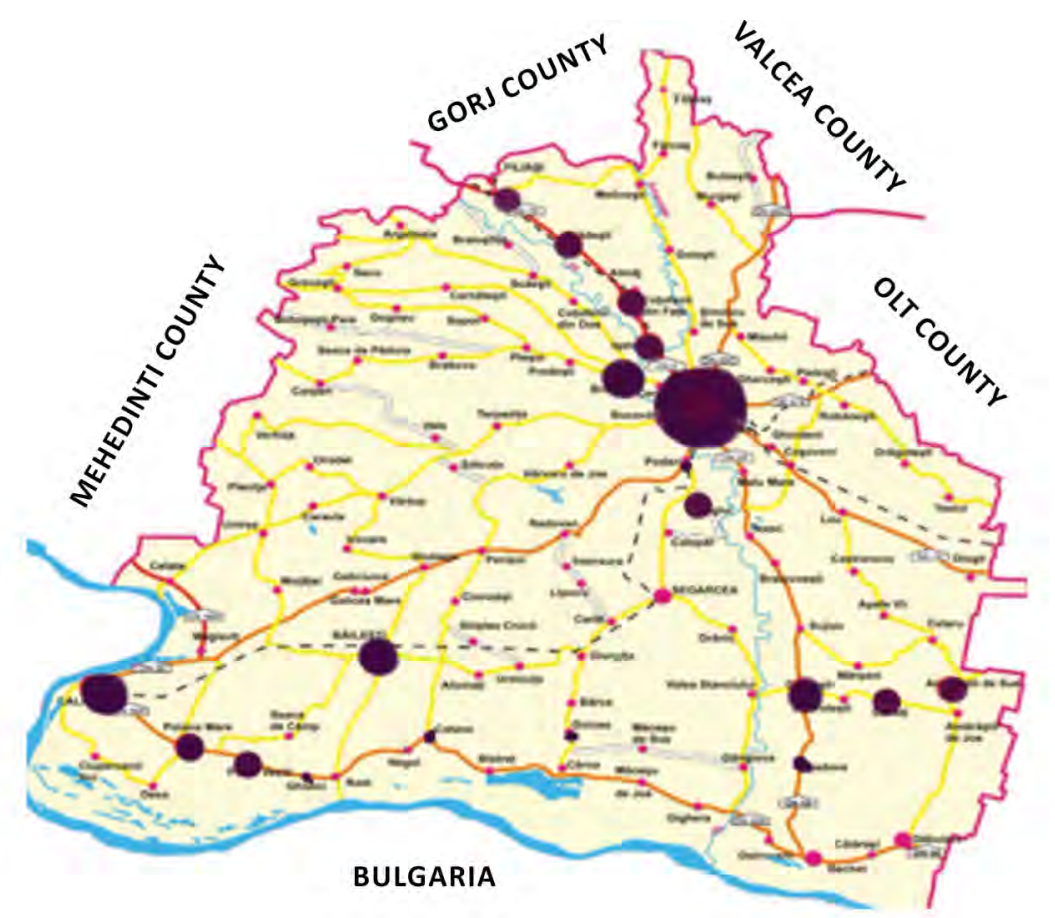

FIGURE 3. The distribution of cases from the Dolj county

pressure, 43 patients $(17.6 \%)$ - with other cardiovascular injuries; 44 cases of obesity (17.9\%), diabetes -32 cases (13.1\%); there also were 8 cases of patients with cancers.

The dominant symptoms were cough - 110 $(57.9 \%)$ and fever - 86 (45.3\%); pulmonary x-rays showed aspects of interstitial pneumonia or unique/ multiple opacities in $54.5 \%$ of the cases (Table 2).

TABLE 2. Clinical and radiological aspects in COVID-19 patients

\begin{tabular}{|l|c|}
\hline Clinical symptoms (190) & $\mathrm{N}(\%)$ \\
\hline Cough & $110(57.9 \%)$ \\
\hline Fever & $86(45.3 \%)$ \\
\hline Shiver & $46(24.2 \%)$ \\
\hline Dyspnea & $40(21.1 \%)$ \\
\hline Dysphagia & $42(22.1 \%)$ \\
\hline Rhinorrhea & $14(7.4 \%)$ \\
\hline Chest pains & $11(5.8 \%)$ \\
\hline Myalgia & $28(14.7 \%)$ \\
\hline Anosmia & $27(14.2 \%)$ \\
\hline Ageusia & $22(11.6 \%)$ \\
\hline Cephalea & $24(12.6 \%)$ \\
\hline Asthenia & $15(7.9 \%)$ \\
\hline Diarrhea & $11(5.8 \%)$ \\
\hline Inappetence & $10(5.3 \%)$ \\
\hline Arthralgia & $7(3.7 \%)$ \\
\hline Dizziness & $3(1.6 \%)$ \\
\hline Radiological aspect (178) & $81(45.5 \%)$ \\
\hline Normal & $44(24.7 \%)$ \\
\hline Inters & $53(29.7 \%)$ \\
\hline &
\end{tabular}

$176(78.1 \%)$ patients had received antiviral medication: $\quad 70$ cases $\quad-$ Lopinavir/Ritonavir (LPV/r)+Hydroxycloroquine (HCQ), 53 cases LPV/r, 50 cases - HCQ, 3 cases - HCQ+Darunavir/ Cobicistat; 6 patients were treated also with Tocilizumab; 18 cases need corticotherapy.

The most dominant forms of disease were the mild ones -117 cases $(47.8 \%)$, medium forms (45 cases) and severe ones (28 cases) - 18.4\% and respectively, $11.4 \%$ from the whole number of cases; 55 patients (22.4\%) were asymptomatic. Children presented mild disease forms, the severe ones were found in older patients, who also had comorbidities. 31 patients required admission in the intensive care units, 10 of them being orotracheal intubated and mechanical ventilated; another 25 patients needed extra oxygen administrated by mask or non-invasive mechanical ventilation.

At the end of the study, there were 202 discharged patients: 192 cured (78.4\%), 10 deaths (4.1\%); 43 patients were still being hospitalized. The hospitalization period for the cured cases was 13.5 days (IQR 8, 35 ), with a median of 12 days (IQR 8, 23) for the asymptomatic ones, 15 days (IQR 8, 35) for the mild cases, 15 days $(8,29)$ for the medium ones and 19.5 days (IQR 9, 26) for the severe cases.

Deaths were associated with age over 60 (p < $0.0001)$, high blood pressure $(p=0.01)$ and diabetes $(\mathrm{p}=0.002)$. 


\section{DISCUSSIONS}

The first COVID-19 confirmed case in Romania was reported on the $26^{\text {th }}$ of February 2020, and on the $16^{\text {th }}$ of March the emergency status was declared in the whole country, people returning from risk areas following home isolation or institutionalized quarantine [13]. According to the data from the National Public Healthcare Institute, until the $31^{\text {st }}$ of May 2020, there were 19,257 COVID-19 confirmed cases [12], with an age median of 48 years (IQR 0,99), our group having a lower age median - 39 years (IQR 0,81 ). There were $28.9 \%$ imported cases, people who had returned from countries with very large number of COVID-19 patients (Italy, United Kingdom, Spain), a much larger percentage than the one registered in our country (3.3\%). Healthcare workers COVID-19 confirmed were $11.8 \%$ from our group, very similar to the percentage established in the whole country $-14.8 \%$. In terms of comorbidities, the most frequent one in COVID-19 patients was high blood pressure (33.1\%), diabetes was found in $13.1 \%$ of the cases, data which is very much alike the one from other studies $[14,15]$.

The most frequent symptoms were cough $(57.9 \%)$ and fever $(45.3 \%)$, but in much lower percentages than in other studies which reported fever in over $76 \%$ and cough in over $59 \%$ of the cases [14-18]. On the other hand, we reported anosmia (14.2\%) and ageusia $(11.6 \%)$, in similar percentages to the ones from a study developed in a Milano Hospital [19]. Dysphagia

\section{REFERENCES}

1. Gorbalenya AE, Baker SC, Baric RS et al. Severe acute respiratory syndrome-related coronavirus: The species and its viruses-a statement of the Coronavirus Study Group. bioRxiv.2020:1-15.

2. Anthony S J, Gilardi K, Menachery V D et al. Further Evidence for Bats as the Evolutionary Source of Middle East Respiratory Syndrome Coronavirus. mBio. 2017;8(2):1-13.

3. Azhar EI, El-Kafrawy SA, Farraj SA et al. Evidence for camel-to-human transmission of MERS coronavirus. N Engl J Med. 2014;370:2499-2505.

4. Li W, Shi Z, Yu M et al. Bats are natural reservoirs of SARS-like coronaviruses. Science. 2005;310:676-679.

5. Shang J, Gang Ye, Ke Shi et al. Structural basis of receptor recognition by SARS-CoV-2. Nature. 2020;581:221-24.

6. Chinese Center for Disease Control and Prevention. The Epidemiological Characteristics of an Outbreak of 2019 Novel Coronavirus Diseases (COVID-19) - China, 2020 . Available from: http://www. ourphn.org.au/wp-content/uploads/20200225-Article-COVID-19.pdf.

7. CDC. 2019 Novel Coronavirus, Wuhan, China: 2019 Novel Coronavirus (2019-nCoV) in the U.S. Centers for Disease Control and Prevention (CDC). Available at https://www.cdc.gov/ coronavirus/2019-ncov/cases-in-us.

8. European Centre for Disease Prevention and Control (ECDC). Coronavirus disease 2019 (COVID-19) pandemic: increased was present in $22.1 \%$ of the patients, somewhat lower percentages $(17.4 \%, 13.9 \%)$ were reported by other authors $[14,16]$. Most cases were mild and medium, the severe ones, $11.4 \%$ of the cases, were found mostly in patients with comorbidities (high blood pressure, diabetes, cancers), just like in other published papers of the medical literature $[10,14,16,17]$. Death rate was $4.1 \%$, lower than the one registered across the whole country $-6.5 \%$ [12], but almost double compared to the one reported by $\mathrm{Wu} \mathrm{Z}$ et al. $-2.4 \%$ [10].

The study's limitations are represented by the somehow small number of cases; the treatment's influence wasn't analyzed; no associations between the clinical forms and the paraclinical parameters were evaluated.

\section{CONCLUSIONS}

The epidemiological link proved very useful in orientating towards a diagnosis, especially for the imported cases, the family and work outbreaks.

The most frequent clinical symptoms of the COVID-19 patients who were admitted in our hospital were cough and fever, but an important number also presented without any fever, with symptoms such as anosmia and ageusia.

Mild disease forms represented the majority, the severe forms were found in elderly patients with comorbidities. Deaths were associated with advanced age, high blood pressure and diabetes.

Conflict of interest: none declared Financial support: none declared

transmission in the EU/EEA and the UK - seventh update - 25 March 2020. Stockholm: ECDC; 2020. Available from: https://www.ecdc. europa.eu/sites/default/files/documents/RRA-seventh-updateOutbreak-of-coronavirus-disease-COVID-19.pdf.

9. Fei Zhou TY, Ronghui D, Guohui F et al. Clinical course and risk factors for mortalityof adult inpatients with COVID-19 in Wuhan, China: A retrospective cohort study. The Lancet. 2020;395:1054-62.

10. Wu Z, McGoogan JM. Characteristics of and Important Lessons From the Coronavirus Disease 2019 (COVID-19) Outbreak in China: Summary of a Report of 72, 314 Cases From the Chinese Center for Disease Control and Prevention. JAMA. 2020;323(13):1239-42.

11. Institutul National de Sanatate Publica. Distribuţia pe judeţe a cazurilor confirmate cu COVID-19 în România. Available from: https:// instnsp.maps.arcgis.com/apps/opsdashboard/index.html\#/5eced7965 95b4ee585bcdba03e30c127 -accesat 31 mai2020.

12. Centrul National de Supraveghere si Control al Bolilor Transmisibile. COVID-19 - Raport saptamanal de supraveghere. Available from: https://www.cnscbt.ro/index.php/analiza-cazuri-confirmatecovid19/1761-raport-saptamanal-episaptamana20/file -accesat 31 mai 2020.

13. Decret nr. 195 din 16 martie 2020 privind instituirea stării de urgenţă pe teritoriul României, publicat în Monitorul Oficial nr. 212 din 16 martie 2020. 
14. Wang D, Hu B, Hu C, Zhu F, Liu X, Zhang J, Wang B et al. Clinical Characteristics of 138 Hospitalized Patients With 2019 Novel Coronavirus-Infected Pneumonia in Wuhan, China. JAMA. 2020;323(11):1061-9.

15. Zhang JJ, Dong X, Cao YY et al. Clinical characteristics of 140 patients infected with SARS-CoV-2 in Wuhan, China [published online ahead of print, 2020 Feb 19]. Allergy. 2020;10.1111/all.14238.

16. Guan WJ, Ni ZY, Hu Y et al. Clinical characteristics of coronavirus disease 2019 in China. N Engl J Med. 2020;382:1708-20.

17. Chen $N$, Zhou M, Dong $X$ et al. Epidemiological and clinical characteristics of 99 cases of 2019 novel coronavirus pneumonia in
Wuhan, China: A descriptive study. Lancet. 2020;395(10223): 507-513.

18. Wu J, Wu X, Zeng W et al. Chest CT Findings in Patients With Coronavirus Disease 2019 and Its Relationship With Clinical Features. Invest Radiol. 2020;55(5):257-261.

19. Giacomelli A, Pezzati L, Conti F et al. Self-reported olfactory and taste disorders in SARS-CoV-2 patients: A cross-sectional study [published online ahead of print, 2020 Mar 26]. Clin Infect Dis. 2020; ciaa330. 